\title{
The multi-objective optimization model for a sustainable manufacturing system design
}

\author{
Reda Nujoom, Ahmed Mohammed, Qian Wang and Nick Bennett \\ School of Engineering, University of Portsmouth \\ Portsmouth, UK \\ Reda.Nujoom@port.ac.uk
}

\begin{abstract}
In the past decade, there has been a growing concern about the environmental protection in the public society as governments in many countries have been enforcing everstricter environmental policies and regulations in industry by promoting energy saving and low carbon dioxide $\left(\mathrm{CO}_{2}\right)$ emissions in manufacturing activities. Development of sustainable manufacturing systems is considered as one of effective solutions to minimize the environmental impact. Lean manufacturing can also be helpful for achieving a sustainable manufacturing system as it can reduce production wastes and increase manufacturing efficiency. Nevertheless, the lean approach does not include a consideration in energy consumption and $\mathrm{CO}_{2}$ emissions when designing a lean manufacturing system. This paper addresses these issues by evaluating a sustainable manufacturing system design by considering a measurement of energy consumption and $\mathrm{CO}_{2}$ emissions. To this aim, a multi-objective mathematical model is developed incorporating the economic and ecological constraints in terms of minimization of the total cost, energy consumption and $\mathrm{CO}_{2}$ emissions for a manufacturing system design. The study also addresses a decision making in the number of machines, the number of air conditioning units and the number of bulbs involved in each process of the manufacturing system in conjunction with a quantity of material flow for processing the products. A real case study was used for examining the validation and applicability of the developed sustainable manufacturing system model.
\end{abstract}

Keywords-sustainable manufacturing systems; energy consumption; $\mathrm{CO}_{2}$; lean manufacturing; environmental constraints; multi-objectives.

\section{INTRODUCTION}

To develop a sustainable manufacturing system, system designers need not merely to apply traditional methods to improve system efficiency and productivity but also to examine the environmental impact on the developed system [1]. The traditional manufacturing system design is involved in determination and analysis of such as material-handling methods, system capacities, production methods, material flow, shop-floor layouts, system flexibilities and operations. Nevertheless, there is an environmental consideration that needs also to be addressed today; this leads to a new challenge for manufacturing system designers to develop an effective approach incorporating environmental parameters or constraints [2]. In the past decade, the concept such as sustainable manufacturing systems has been used for promoting a balance between the environmental impact and the economic performance for production [3]. The concept of manufacturing sustainability may be defined as the creation of manufactured products by minimizing negative environmental impacts on usage of energy or natural resources [4]. This concept has usually been implemented by dealing with the environmental problems as a separate objective in the process synthesis at an early stage. In this approach, each of environmental aspects is considered as a separate objective together with other classical objectives in maximizing system productivity or system efficiency and or minimizing cost of the desired product, which forms a multi-objective optimization (MOO) problem [3].

Moreover, development of a sustainable manufacturing system design should also consider lean methods as it has become a trend in modern manufacturing enterprises for improving system efficiency and productivity without additional investments. Lean manufacturing is a systematic approach to eliminate non-value added wastes in various forms and it enables continuous improvement [4]. These wastes are overproduction, waiting for parts to arrive, unnecessary movement of materials, the waste in processing, unnecessary inventory, excess motion and the waste of rework [5]. However, traditional lean manufacturing method does not consider environmental wastes such as waste of energy and $\mathrm{CO}_{2}$ emissions which also need to be identified as these wastes add no values on manufactured products $[4,5]$. Consequently, it is important to optimize the traditional lean manufacturing system design to achieve the sustainability and make a balance under the economic and ecological constraints. Moreover, industrial factories consume a massive amount of energy and produce a huge amount of $\mathrm{CO}_{2}$ emissions, which lead to a huge amount of costs that need to be considered in the manufacturing system design.

There are a few studies in considering environmental aspects related to manufacturing and sustainable manufacturing system. Lind et al. argued that manufacturing system designers need to not merely rely on traditional methods in improvements of system efficiency and productivity but also incorporate environmental considerations into design and operation of the developed manufacturing processes or systems [6]. Wang et al. proposed the process integration (PI) method that was used for evaluating $\mathrm{CO}_{2}$ emissions for a steel industry [7]. Branham et al. used the quantitative thermodynamic analysis for quantifying energy in different categories applied into manufacturing processes or systems [8]. Guillen-Gosalbez and Grossmann developed a mathematical model named as a bi-criterion stochastic mixed-integer nonlinear program 
(MINLP) used for the maximization of the network present value and the minimization of the environmental impact on a sustainable chemical supply chains design [9].

The multi-objective optimization approach is one of the mathematical methods that can be used for modelling a manufacturing system by satisfying a number of conflicting objectives (such as energy consumption, $\mathrm{CO}_{2}$ emissions and costs) in which each objective needs to be optimised based on a separate objective function. Li et al. used a multi-objective mixed integer non-linear model incorporating environmental and economic factors for design and optimization of chemical process [10]. Jamshidi et al. developed a multi-objective mathematical model to solve a number of issues of a supply chain design in terms of minimization of annual cost while considering environmental effects [11].

This paper presents an investigation into a sustainable manufacturing system design through the development of a multi-objective model. The developed model was used for examining the configuration and performance measures of the proposed sustainable manufacturing system design in terms of (1) number of machines involved in each process in the manufacturing system (2) number of air conditioning units and number of bulbs involved in each process (3) optimal material quantity flows along the line and (4) a compromised solution among conflicting objectives by minimizing the total investment cost for establishing the manufacturing system, minimizing the amount of energy consumed by the machines involved in each process in the manufacturing system and minimizing the $\mathrm{CO}_{2}$ emissions released from the machines involved in each process in the manufacturing system. The $\varepsilon-$ constraint approach was used to reveal non-inferior solutions obtained based on the developed mathematical model; followed by an employment of the max-min approach in order to select the best non-inferior solution.

\section{PROBLEM STATEMENT AND MODEL FORMULATION}

Figure 1 illustrates a framework of a sustainable manufacturing system design which consists of operation machines, air conditioning systems, illumination systems and other supportive equipment such as compressors which supply compressed air to some machines. Energy and $\mathrm{CO}_{2}$ emissions are generated by either combusting fossil fuels directly or using electricity which is generated indirectly by using fossil fuels or renewable resources. To achieve the sustainability of a manufacturing system design, energy consumed by all those equipment in the manufacturing system as well as the amount of $\mathrm{CO}_{2}$ emissions released from the manufacturing system need to be quantified in conjunction with the total cost that also needs to be considered for establishing the manufacturing system. In this study, these parameters are mathematically formulated as a multi-objective optimization model aimed at obtaining a trade-off decision among minimization of total investment cost for establishing the manufacturing system (equation 1), minimization of the total energy consumed by the manufacturing system (equation 2), and minimization of the total amount of $\mathrm{CO}_{2}$ emissions (equation 3 ) as described below.

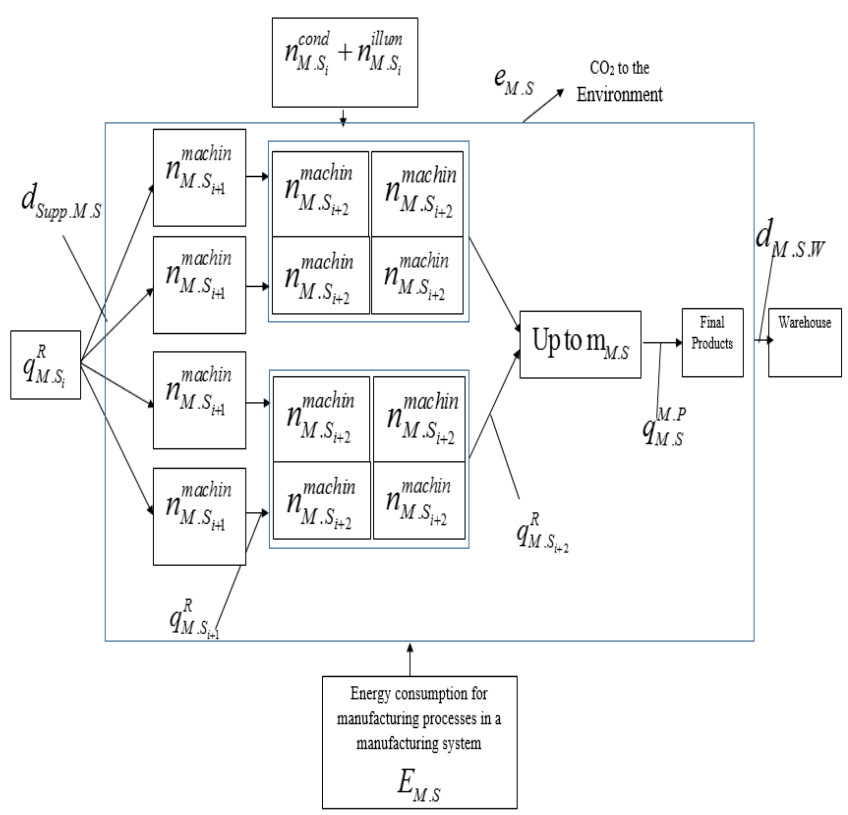

Fig. 1. Strcuture of a sustainable manufacturing system design

The following notations are used for formulating the mathematical model:

Sets:

$m_{M . S_{i}}:$ number of processes involved in a manufacturing system, where $i \in\left\{1,2, \ldots, m_{M . S}\right\}$

Parameters:

$C_{M . S}^{\text {fixed }}(\mathrm{GBP})$ : fixed cost of a manufacturing system

$C_{M . S}^{R}(\mathrm{GBP})$ : unit raw materials cost

$C_{M . S}^{M . P}(\mathrm{GBP})$ : unit manufacturing cost

$C_{M . S}^{T . R}(\mathrm{GBP})$ : unit transportation cost of raw materials

$C_{M . S}^{T . M . P}(\mathrm{GBP})$ : unit transportation cost of products

$d_{\text {Supp.M.S }}$ (mile): distance from a supplier to a manufacturing system

$d_{M . S . W}($ mile): distance from a manufacturing system to a

warehouse

$V(\mathrm{~kg})$ : capacity per vehicle

$E_{M . S}(\mathrm{KWh})$ : Energy consumption for a manufacturing

system

$E_{M . S_{i}}^{\text {mach }}(\mathrm{KWh})$ : energy consumption for a machine involved in process $i$ in manufacturing system, where

$i \in\left\{1,2, \ldots . m_{M . S}\right\}$ 
$E_{M . S_{i}}^{\text {air comp }}(\mathrm{KW})$ : energy consumption of compressed air needed for a machine involved in process $i$ in a manufacturing system

$E_{M . S_{i}}^{c o n d}(\mathrm{KWh})$ : energy consumption for an air conditioning system in a manufacturing system

$E_{M . S_{i}}^{\text {illum }}(\mathrm{KWh})$ : energy consumption for an illumination system in a manufacturing system

$N_{M . S_{i}}^{\text {mach }}(\mathrm{Kw})$ : installed power for a machine involved in

process $i$ in a manufacturing system

$N_{M . S_{i}}^{\text {air comp }}(\mathrm{Kw})$ : installed power for a compressor in a manufacturing system

$N_{M . S_{i}}^{\text {cond }}(\mathrm{Kw})$ : installed power for an air conditioning unit in a manufacturing system

$N_{M . S_{i}}^{\text {illum }}(\mathrm{Kw})$ : installed power for illumination in a

manufacturing system

$\mathfrak{R}_{M . S_{i}}(\mathrm{~kg} / \mathrm{h})$ : manufacturing rate for a machine involved in process $i$ in a manufacturing system

$\tau_{M . S_{i}}(\mathrm{~h})$ : operating time for a machine involved in process $i$ in a manufacturing system

$G_{M . S}(\mathrm{Kg})$ : mass production per month for a manufacturing system

$\psi_{M . S_{i}}(\%)$ : total waste ratio for a machine involved in process $i$ in a manufacturing system

$\mu_{M . S_{i}}(\%)$ : efficiency for a machine involved in process $i$ in a manufacturing system

$v_{M . S_{i}}^{\text {air comp }}\left(\mathrm{m}^{3} / \mathrm{h}\right)$ : compressed air used for a machine involved

in process $i$ per hour in a manufacturing system

$\rho_{M . S_{i}}^{\text {air comp }}\left(\mathrm{m}^{3} / \mathrm{h}\right)$ : capacity of compressed air in cubic meter per

hour of a compressor for a machine involved in process $i$ in a manufacturing system

$\Phi_{M . S_{i}}^{\text {cond }}$ : number of machines being served by one air conditioning unit in a manufacturing system

$\varphi_{M . S_{i}}^{\text {illum }}:$ number of bulbs needed to serve one machine in a manufacturing system

$e_{M . S}(\mathrm{~kg} / \mathrm{kWh})$ : amount of $\mathrm{CO}_{2}$ emissions per $\mathrm{kWh}$ released from a manufacturing system due to manufacturing the products

$e_{M . S_{i}}^{\text {mach }}(\mathrm{kg} / \mathrm{kWh})$ : amount of $\mathrm{CO}_{2}$ emissions per $\mathrm{kWh}$ released from a machine involved in process task $i$

$e_{M . S_{i}}^{\text {air comp }}(\mathrm{kg} / \mathrm{kWh})$ : amount of $\mathrm{CO}_{2}$ emissions per $\mathrm{kWh}$ released from a compressor involved in process task $i$ $e_{M . S_{i}}^{\text {cond }}(\mathrm{kg} / \mathrm{kWh})$ : amount of $\mathrm{CO}_{2}$ emissions per $\mathrm{kWh}$ released from an air conditioning system involved in process task $i$
$e_{M . S_{i}}^{\text {illum }}(\mathrm{kg} / \mathrm{kWh}):$ amount of $\mathrm{CO}_{2}$ emissions per $\mathrm{kWh}$ released from an illumination system involved in process task $i$

$e_{M . S_{i}}(\mathrm{~kg} / \mathrm{kWh})$ : amount of $\mathrm{CO}_{2}$ emissions per $\mathrm{kWh}$ released from a machine, an air conditioning system and an illumination system involved in process $i$ in a manufacturing system

$\omega_{M . S_{i}}(\mathrm{~kg} / \mathrm{kwh}): \mathrm{CO}_{2}$ emission factor using different energy sources in a manufacturing system

Decision variables:

$q_{M . S_{i}}^{R}(\mathrm{Kg})$ : mass of material involved in process $i$ in a manufacturing system

$q_{M . S_{i+1}}^{R}(\mathrm{Kg})$ : mass of materials transferred from process $i$ in a manufacturing system

$q_{M . S}^{M . P}(\mathrm{Kg})$ : mass of materials Shipped as a final products

$n_{M . S_{i}}^{\text {mach }}$ (unit): number of machines involved in process $i$ in a

manufacturing system, where $i \in\left\{1,2, \ldots, m_{M . S}\right\}$

$n_{M . S_{i}}^{\text {cond }}$ (unit): number of air conditioning units involved in process $i$ in a manufacturing system,

where $i \in\left\{1,2, \ldots, m_{M . S}\right\}$

$n_{M . S_{i}}^{\text {illum }}$ (unit): number of bulbs involved in process $i$ in a manufacturing system, where $i \in\left\{1,2, \ldots ., m_{M . S}\right\}$

Based on the aforementioned notations, the multiobjective mathematical model can be formulated as follows:

Objective function 1

$$
\begin{aligned}
& \text { MinZ } Z_{1}=C_{M . S}^{\text {Land }}+C_{M . S}^{\text {Buldings }} \\
& +C_{M . S}^{\text {Equlpments }}+C_{M . s}^{\text {Services }}+C_{M . s}^{\text {Saleries }} \\
& +C_{\text {One kg }}^{R} q_{M . S}^{R}+C_{\text {One unit }}^{M . P} q_{M . S}^{M . P} \\
& +C_{\text {One kg }}^{R} \frac{q_{M . S}^{R}}{V} d_{\text {Supp.M.S }}+C_{\text {One unit }}^{M . P} \frac{q_{M . S}^{M . P}}{V} d_{M . S . W}
\end{aligned}
$$

Objective function 2

$$
\begin{aligned}
& \operatorname{Min} Z_{2}=\sum_{i=1}^{m_{M . S}}\left(\frac{q_{M . S_{i}}^{R}}{\mathfrak{R}_{M . S_{i}} \mu_{M . S_{i}}} N_{M . S_{i}}^{\text {mach }} n_{M . S_{i}}^{\text {mach }}\right. \\
& +\frac{q_{M . S_{i}}^{R}}{\mathfrak{R}_{M . S_{i}} \mu_{M . S_{i}}} \frac{N_{M . S_{i}}^{\text {air comp }}}{\rho_{M . S_{i}}^{\text {air comp }}} v_{M . S_{i}}^{\text {air comp }} n_{M . S_{i}}^{\text {mach }} \\
& +N_{M . S_{i}}^{\text {cond }} n_{M . S_{i}}^{\text {cond }} \frac{\left.q_{M . S_{i+1}}^{R}+N_{M . S_{i}}^{\text {illum }} n_{M . S_{i}}^{\text {illum }} \frac{q_{M . S_{i+1}}^{R}}{G_{M . S}}\right)}{G_{M . S}}
\end{aligned}
$$


Objective function 3

$M i n Z_{3}=\sum_{i=1}^{m_{M . S}}\left[\omega_{M . S_{i}}\left(E_{M . S_{i}}^{\text {mach }} q_{M . S_{i}}+E_{M . S_{i}}^{\text {air comp }}+E_{M . S_{i}}^{\text {cond }}+E_{M . S_{i}}^{\text {illum }}\right)\right]$

Constraints:

$q_{M \cdot S_{i+1}}^{R} \leq q_{M \cdot S_{i}}^{R}$

$\mathfrak{R}_{M . S_{i}} n_{M . S_{i}}^{\text {mach }} \geq q_{M . S_{i+1}}^{R}$

$q_{M . S_{i}}^{R}, q_{M . S_{i+1}}^{R}, q_{M . S}^{M . P} \geq 0$

$\Phi_{M . S_{i}}^{\text {cond }} n_{M . S_{i}}^{\text {cond }} \geq n_{M . S_{i}}^{\text {machin }}$

$n_{M . S_{i}}^{\text {illum }} \geq \varphi_{M . S_{i}}^{\text {illum }} n_{M . S_{i}}^{\text {machin }}$

Where, equations 4-6 are quantity constraints; and equation 7 and 8 are constraints in numbers of machines, air conditioning and bulbs.

\section{APPLICATION AND EVALUATION}

In order to examine the applicability and the validation of the developed multi-objective optimisation model as described above, a real case study was applied. The production line comprises 8 different processing tasks, each process task may involve a number of machines and each machine has consumption of energy and mass inputs with different specifications. Table I shows the manufacturing process in which the symbols represent each task of a manufacturing process to produce plastic and woven sacks in a woven sacks factory. Table II shows the data collected from the real production line at the woven sacks company. In this case, the production line is powered by electricity which is generated using solar energy. LINGO $^{11}$ software was used for computing results based on the developed multi-objective mathematical model.

TABLE I. MANUFACTURING PROCESSES TASKS FOR PRODUCING PLASTIC AND WOVEN SACKS

\begin{tabular}{|c|c|c|}
\hline Tasks & Description & Predecessors \\
\hline R.M & Raw material (Polypropylene) & None \\
\hline G & $\begin{array}{c}\text { Extruding the Polypropylene to } \\
\text { make stands }\end{array}$ & R.M \\
\hline W & $\begin{array}{c}\text { Weaving the strands into } \\
\text { rolls of sacks }\end{array}$ & $\mathrm{G}$ \\
\hline L & Laminating the rolls & W \\
\hline P & Printing and branding & L \\
\hline C & Cutting blown inner-film in to bags & P \\
\hline K & Liner stick, inserts and smoothes & C \\
\hline S & Film sewn into bag & K \\
\hline B & $\begin{array}{c}\text { End product compressed using } \\
\text { baling machines }\end{array}$ & $\mathrm{S}$ \\
\hline
\end{tabular}

TABLE II. DATA COLLECTED FROM A PLASTIC AND WOVEN SACKS COMPANY

\begin{tabular}{|c|}
\hline$C_{M . S}^{\text {fixed }}(\mathrm{GBP}): 6000000, C_{M . S}^{R}(\mathrm{GBP} / \mathrm{kg}): 2, C_{M . S}^{M . P}(\mathrm{GBP}): 3$ \\
\hline $\begin{array}{c}C_{M . S}^{T . R}(\mathrm{GBP}): 2, C_{M . S}^{T . M . P}(\mathrm{GBP}): 2, d_{\text {Supp.M.S }}(\text { mile }): 50 \\
d_{M . S . W}(\text { mile }): 10, V(\mathrm{~kg}):=20000\end{array}$ \\
\hline $\begin{array}{c}m_{M . S}=8, \mathfrak{R}_{M . S_{i}}(\mathrm{~kg} / \mathrm{h}): 1852,1815,1742,1716,1699,1665,1660 \\
\text { and } 1643, \text { where } i \in\left\{1,2, \ldots ., m_{M . S}\right\}, \mu_{M . S_{i}}(\%): 80 \text { for all } \\
\text { machines }\end{array}$ \\
\hline $\begin{array}{l}N_{M . S_{i}}^{\text {mach }}(\mathrm{Kw}): 200,20,7,40,7,0,0.8 \text { and } 4, N_{M . S_{i}}^{\text {air comp }}(\mathrm{Kw}): 200, \\
\rho_{M . S_{i}}^{\text {air comp }}\left(\mathrm{m}^{3} / \mathrm{h}\right): 666, v_{M . S_{i}}^{\text {air comp }}\left(\mathrm{m}^{3} / \mathrm{h}\right): 5,4,13,0,7,5,20 \text { and } 0\end{array}$ \\
\hline$N_{M . S_{i}}^{\text {cond }}(\mathrm{Kw}): 2.2, N_{M . S_{i}}^{\text {illum }}(\mathrm{Kw}): 0.4, \Phi_{M . S_{i}}^{\text {cond }}: 2, \varphi_{M . S_{i}}^{\text {illum }}: 15$ \\
\hline$G_{M . S}(\mathrm{Kg}): 831540, \omega_{M . S_{i}}(\mathrm{~kg} / \mathrm{kwh}): 0.05$ \\
\hline
\end{tabular}

In aiming to obtain non-inferior solutions, $\varepsilon$-constraint approache was utilized [12]. In this approach, the developed multi-objective model can be converted into a single-objective by adding some constraints; the higher priority objective (total energy consumption) is considered to be an objective function (equation 9) and the other two objective functions (the total cost and the total $\mathrm{CO}_{2}$ emissions) are shifted to be $\varepsilon$-based constraints; i.e. (equation 10) restricts the value of the first objective function to be less than or equal to $\varepsilon_{1}$ which gradually varies between the minimum value and the maximum value for objective function one (equation 11). Equation 12 restricts the value of the third objective function to be less than or equal to $\varepsilon_{2}$ which gradually varies between the minimum value and the maximum value for objective function three (equation 13). The selection of any objective to be an objective function or a constraint is not limited. The equivalent solution formula $\mathrm{Z}$ is presented as follows:

$\operatorname{MinZ}_{2}$

Eq. (9) is subject to the following constrains:

$Z_{1} \leq \varepsilon_{1}$

$\left(Z_{1}\right)^{\min } \leq \varepsilon_{1} \leq\left(Z_{1}\right)^{\max }$

$Z_{3} \leq \varepsilon_{2}$

$\left(Z_{3}\right)^{\min } \leq \varepsilon_{2} \leq\left(Z_{3}\right)^{\max }$

And additional constraints including (equation. 4-8).

Table III, illustrates the non-inferior solutions that were obtained by an assignment of $\varepsilon$-values from 9639090 to 13668548 for objective (1) and from $46380 \times 10^{6}$ to $87630 \times 10^{6}$ for objective (3). It can be noted in Table III that the values of 
objective (1) and (3) are highly sensitive to the assigned values of $\varepsilon_{1}$ and $\varepsilon_{2}$ which vary between the minimum value and the maximum value for objectives (1) and (3), respectively. As an example, solution 1 obtained by an assignment of $\varepsilon_{1}=9639090$, and $\varepsilon_{2}=46380 \times 10^{6}$ accordingly, the minimum total cost for establishing the manufacturing system is 9639090 GBP, the minimum total amount of energy consumed by the manufacturing system is $679749 \mathrm{kWh}$ and the minimum total amount of $\mathrm{CO}_{2}$ emissions released from the manufacturing system is $46380 \times 10^{6}$ $\mathrm{kg} / \mathrm{kWh}$. As shown in Table IV, each solution has a potential group of number of machines, number of air conditioning units and number of bulbs that is involved in process task $i$ in the manufacturing system. For instance, in solution 1, number of machines involved in process task $i$ in a manufacturing system $\left(n_{M . S_{i}}^{\text {mach }}\right)$ where $i \in\{1,2,3,4,5,6,7,8\}$ are $(4,32$, $3,5,12,12,50$ and 4 ), number of air conditioning units involved in process task $i\left(n_{M . S_{i}}^{\text {cond }}\right)$ are $(2,16,2,3,6,6,25$ and 2) and number of bulbs $\left(n_{M . S_{i}}^{\text {illum }}\right)$ are $(60,480,45,75,180,180$, 750 and 60).

TABLE III. NON-INFERIOR SOLUTIONS OBTAINED BY USING THE $\mathcal{E}$ CONSTRAINT APPROACH

\begin{tabular}{|l|c|l|l|l|l|}
\hline \multirow{2}{*}{$\begin{array}{l}\text { No of } \\
\text { solutions }\end{array}$} & \multicolumn{2}{|c|}{$\varepsilon$-values } & \multicolumn{3}{|c|}{ Objective function solutions } \\
\cline { 2 - 6 } & $\varepsilon_{1}$ & $\varepsilon_{2}$ & Min $\mathrm{Z}_{1}$ & Min $\mathrm{Z}_{2}$ & Min $\mathrm{Z}_{3}$ \\
\hline 1 & 9639090 & $46380 \times 10^{6}$ & 9639090 & 679749 & $46380 \times 10^{6}$ \\
\hline 2 & 10646455 & $566305 \times 10^{5}$ & 10909090 & 1036639 & $60130 \times 10^{6}$ \\
\hline 3 & 11653820 & $669425 \times 10^{5}$ & 12288819 & 1236545 & $73880 \times 10^{6}$ \\
\hline 4 & 12661185 & $77255 \times 10^{6}$ & 13668548 & 1436451 & $87630 \times 10^{6}$ \\
\hline
\end{tabular}

A pairwise comparison among the three conflicting objectives is illustrated in Figure 2 (chart A and chart B). The results shown in Figure 2 indicate that the non-inferior solution 1 , which has less energy consumption compared to the other solutions. This leads to a reduction of the total cost and the total $\mathrm{CO}_{2}$ emissions. Moreover, as shown in Table IV, the number of machines involved in process task $i$ in a manufacturing system are less than the number of other solutions. By balancing the three objectives with $\varepsilon_{1}=9639090$,

and $\varepsilon_{2}=46380 \times 10^{6}$, it leads to compromise solution 1 , which includes an installation of machines $(4,32,3,5,12,12,50$ and 4), air conditioning units (2, 16, 2, 3, 6, 6, 25 and 2) and bulbs $(60,480,45,75,180,180,750$ and 60$)$ for processes task $(1,2$, $3,4,5,6,7,8)$ in the manufacturing system. This solution gives a total amount of energy consumption $679749 \mathrm{kWh}$, the total amount of $\mathrm{CO}_{2}$ emissions $46386 \times 106 \mathrm{~kg} / \mathrm{kWh}$ and the total investment cost 9639090 GBP.
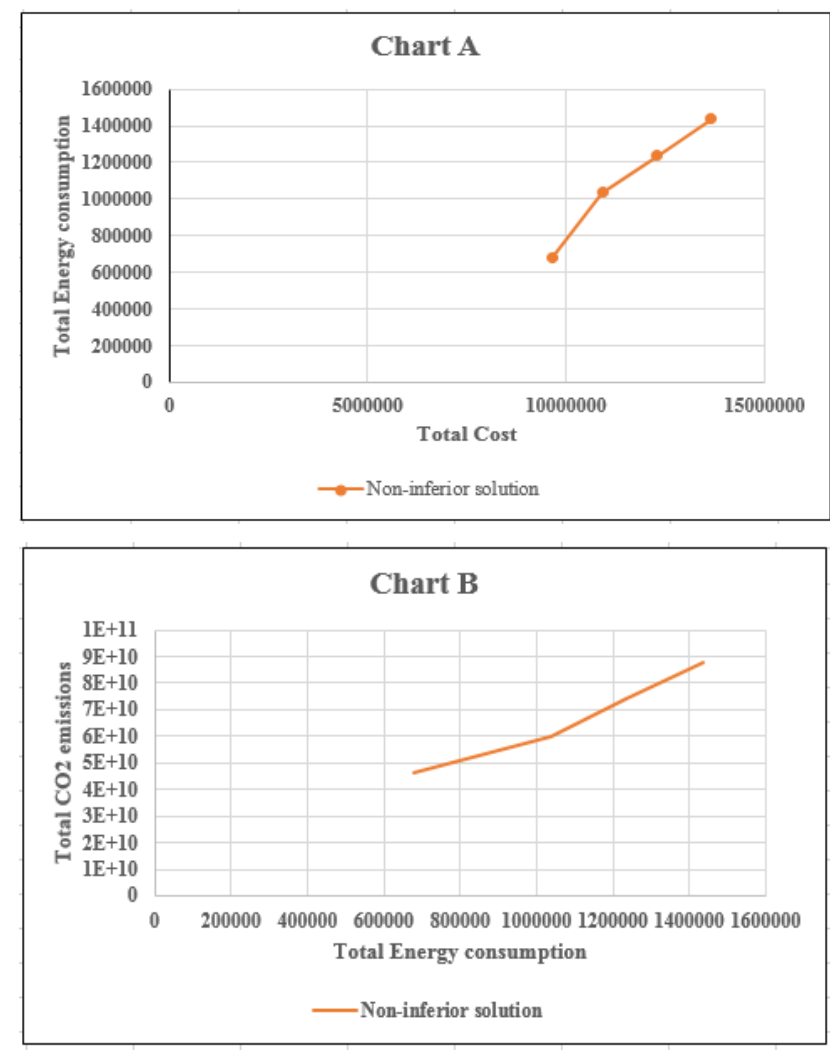

Fig. 2. Comparison between solutions obtained

In order to design a sustainable manufacturing system based on the obtained solutions using the $\varepsilon$-constraint approach, one of these solutions needs to be selected based on the preferences of decision makers or using the Max-Min approach [13]. Based on this Max-Min approach, solution 2 is determined as the best solution as it has the minimal distance 3.45 to the value of the ideal solution. Table $\mathrm{V}$ shows the number of machines, the number of air conditioning units and the number of bulbs that need to be involved in processes to achieve the sustainable manufacturing system design.

TABLE V. THE BEST SOLUTION FOR A SUSTAINABLE MANUFACTURING SYSTEM DESIGN

\begin{tabular}{|c|c|c|c|}
\hline \multicolumn{4}{|c|}{ The best solution for a sustainable manufacturing system design } \\
\hline $\begin{array}{c}\text { Number of } \\
\text { process task } \\
i\end{array}$ & $\begin{array}{c}\text { Number of } \\
\text { machines } \\
\text { involved in } \\
\text { process } i \text { from } \\
\text { process G up to } \\
\text { process B } \\
\text { mach } \\
n_{M} S_{i}\end{array}$ & $\begin{array}{c}\text { Number of air } \\
\text { conditioning } \\
\text { units } \\
\text { cond }\end{array}$ & $\begin{array}{c}\text { Number of } \\
\text { bulbs } \\
n_{M . S_{i}}^{\text {illum }}\end{array}$ \\
\hline 1 & 4 & 2 & \\
\hline 2 & 40 & 20 & 60 \\
\hline 3 & 3 & 2 & 600 \\
\hline 4 & 5 & 3 & 75 \\
\hline 5 & 13 & 7 & 195 \\
\hline 6 & 13 & 7 & 195 \\
\hline 7 & 60 & 33 & 900 \\
\hline 8 & 4 & 2 & 60 \\
\hline
\end{tabular}


TABLE IV. NUMBER OF MACHINES, AIR CONDITIONING UNITS AND NUMBER OF BULBS INVOLVED IN PROCESS $I$ IN A MANUFACTURING SYSTEM

\begin{tabular}{|c|c|c|c|c|c|c|c|c|c|c|c|c|c|c|c|c|c|c|c|c|c|c|c|c|}
\hline \multirow[t]{2}{*}{$\begin{array}{l}\text { No of } \\
\text { solutions } \\
\#\end{array}$} & \multicolumn{8}{|c|}{$\begin{array}{c}\text { Number of machines involved in process } i \text {, where } \\
i \in\{1,2,3,4,5,6,7,8\} \text {. From machines } \mathrm{G} \text { up to } \\
\text { machines B } \\
n_{M . S_{i}}^{\text {mach }}\end{array}$} & \multicolumn{8}{|c|}{$\begin{array}{l}\text { Number of air conditioning units involved in } \\
\text { process } i \\
n_{M . S_{i}}^{\text {cond }}\end{array}$} & \multicolumn{8}{|c|}{$\begin{array}{l}\text { Number of bulbs involved in process } i \\
\qquad n_{M . S_{i}}^{\text {illum }}\end{array}$} \\
\hline & 1 & 2 & 3 & 4 & 5 & 6 & 7 & 8 & 1 & 2 & 3 & & 5 & 6 & 7 & 8 & 1 & 2 & 3 & 4 & 5 & 6 & 7 & 8 \\
\hline 1 & 4 & 32 & 3 & 5 & 12 & 12 & 50 & 4 & 2 & 16 & 2 & & 6 & 6 & 25 & 2 & 60 & 480 & 45 & 75 & 180 & 180 & 750 & 60 \\
\hline 2 & 4 & 40 & 3 & 5 & 13 & 13 & 60 & 4 & 2 & 20 & 2 & & 7 & 7 & 33 & 2 & 60 & 600 & 45 & 75 & 195 & 195 & 900 & 60 \\
\hline 3 & 5 & 40 & 4 & 5 & 14 & 14 & 60 & 4 & 3 & 20 & 2 & & 7 & 7 & 30 & 2 & 75 & 600 & 60 & 75 & 210 & 210 & 900 & 60 \\
\hline 4 & 5 & 45 & 5 & 6 & 16 & 16 & 60 & 5 & 3 & 23 & 3 & & 8 & 8 & 30 & 3 & 75 & 675 & 75 & 90 & 240 & 240 & 900 & 75 \\
\hline
\end{tabular}

Furthermore, this solution shows the optimum delivery plan of the input quantity of materials $\left(q_{M . S_{i}}^{R}\right)$, quantity of materials flow between the machines involved in process task $i\left(q_{M . S_{i+1}}^{R}\right)$ and then shipped as a final product $\left(q_{M . S}^{M . P}\right)$. As shown in Table VI, the optimal decisions in quantity of materials flows through the machines involved in process task 1,2, 3, 4, 5, 6, 7 and 8 are $980000 \mathrm{~kg}, 978040 \mathrm{~kg}, 976084 \mathrm{~kg}, 937040 \mathrm{~kg}, 918299 \mathrm{~kg}$, $889824 \mathrm{~kg}, 868344 \mathrm{~kg}$ and $850660 \mathrm{~kg}$, respectively before being shipped to warehouse as a final product.

Finally, Figure 3 shows the optimal sustainable manufacturing system design model based on the determined solution 2 , which is obtained with $\varepsilon_{1}=9639090$, and $\varepsilon_{2}=$ $46380 \times 10^{6}$ that yields a minimum total cost of 10909090 GBP with the minimum total amount of energy consumption of $1036639 \mathrm{kWh}$ and the minimum total amount of $\mathrm{CO}_{2}$ emissions of $60130 \times 10^{6} \mathrm{~kg}$.

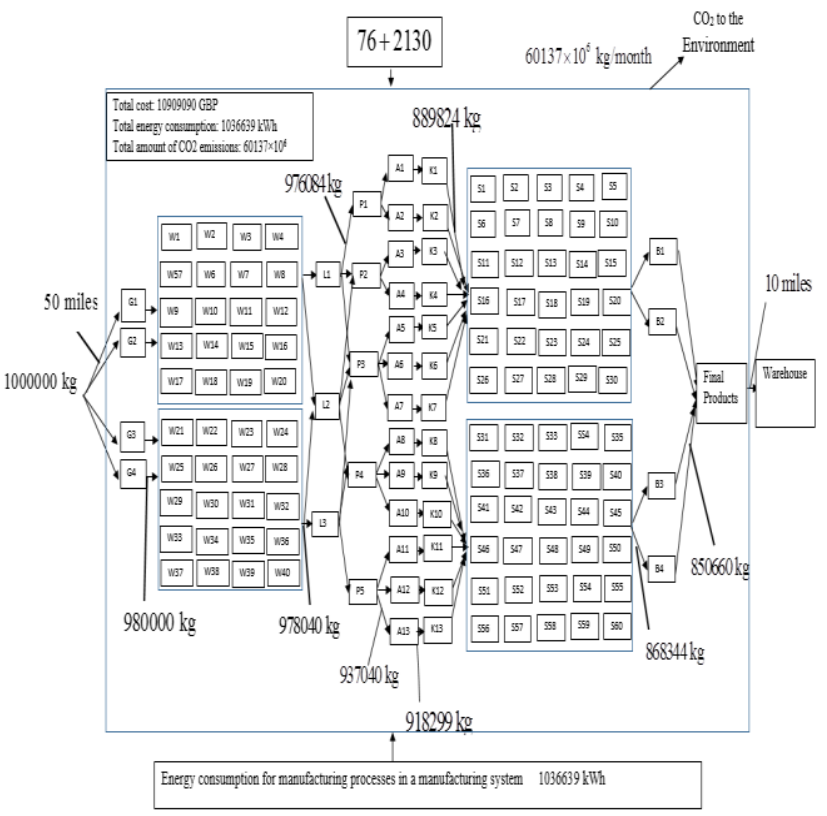

TABLE VI. THE QUANTITY OF MATERIAL FLOW BETWEEN THE PROCESSES INSIDE A SUSTAINABLE MANUFACTURING SYSTEM

\begin{tabular}{|c|c|c|c|c|c|c|c|c|c|}
\hline \multicolumn{1}{|c|}{$q_{M . S_{i}}^{R}$ Where $i \in\{0,1,2,3,4,5,6,7,8\}$} \\
\hline $\begin{array}{c}\text { NO of } \\
\text { solutions } \\
\#\end{array}$ & 0 & 1 & 2 & 3 & 4 & 5 & 6 & 7 & 8 \\
\hline 1 & 985500 & 965200 & 963040 & 960084 & 935805 & 909227 & 881567 & 853478 & 842344 \\
\hline 2 & 1000000 & 980000 & 978040 & 976084 & 937040 & 918299 & 889824 & 868344 & 850660 \\
\hline 3 & 1020000 & 1002000 & 996100 & 994084 & 955150 & 928300 & 904824 & 883344 & 865660 \\
\hline 4 & 1045000 & 1027000 & 1009000 & 991100 & 973050 & 940200 & 919700 & 898400 & 883660 \\
\hline
\end{tabular}

\section{CONCLUSION}

When designing a manufacturing system, engineers used to focus on the key performance indicators in terms of system productivity and capacity; environmental considerations are often overlooked. This paper presents the development of a three-objective mathematical model for optimizing a sustainable manufacturing system design which addresses environmental sustainability relating to manufacturing activities. The developed multi-objective mathematical model can be used as a reference for manufacturing system designers in finding a trade-off solution in minimizing the total investment cost, minimizing the total energy consumption and minimizing the total $\mathrm{CO}_{2}$ emissions released from the manufacturing system. The computational results were validated based on data collected from a real industrial case. The initial results indicate that this is a useful and effective way as an aid for optimizing the traditional manufacturing system design in order to achieve the sustainability under the economic and ecological constraints.

\section{REFERENCES}

[1] S. Lind, B. Krassi, B. Johansson, J. Viitaniemi, J. Heilala, S. Stahre, S. Vatanen, A. Fasth, and C. Berlin, "SIMTER: A Production Simulation Tool for Joint Assessment of Ergonomics, Level of Automation and Environmental Impacts", In the 18th FAIM, Stockholm, pp 5-49, 2008.

[2] M. Paju, J. Heilala, M. Hentula, A. Heikkila, B. Johansson, S. Leong, and K. Lyons, "Framework and 
indicators for a sustainable manufacturing mapping methodology", In the WSC, IEEE, Baltimore, MD, pp 3411-3422, 2010.

[3] H. Taghdisian, M. R. Pishvaie, and F. Farhadi, "Multiobjective optimization approach for green design of methanol plant based on CO2-efficeincy indicator," Journal of Cleaner Production, 2014.

[4] R. Nujoom, Q. Wang, and N. Bennett, (2016). "An Integrated Method for Sustainable Manufacturing Systems Design," In MATEC Web of Conferences, EDP Sciences, vol. 70, 2016, p. 05005.

[5] Q. Wang, S. Lassalle, A. R. Mileham, and G. W, Owen, "Analysis of a linear walking worker line using a combination of computer simulation and mathematical modeling approaches," JMSY, vol. 28, 2009, pp. 64-70.

[6] J. Heilala, S. Vatanen, H. Tonteri, J. Montonen, S. Lind, B. Johansson, and J. Stahre, (2008). "Simulation-based sustainable manufacturing system design," Proceedings of the 2008 Winter Simulation Conference, 2008, pp. 19221930.

[7] C. Wang, M. Larsson, C. Ryman, C. E. Grip, J. O. Wikström, A. Johnsson, and J. Engdahl, "A model on $\mathrm{CO} 2$ emission reduction in integrated steelmaking by optimization methods," IJER, vol. 32, 2008, pp. 10921106.

[8] M. Branham, T. G. Gutowski, A. Jones, and D. P. Sekulic, "A thermodynamic framework for analyzing and improving manufacturing processes," In ISEE. IEEE, San Francisco, CA, 2008, pp. 1-6.

[9] G. Guillén. Gosálbez, and I. E. Grossmann, “Optimal design and planning of sustainable chemical supply chains under uncertainty," AIChE Journal, vol. 55, No. 1, 2009, pp. 99-121.

[10] C. Li, X. ZhangZhang, and S. Suzuki, "Environmentally conscious design of chemical processes and products: multi-optimization method," Chem. Eng. Res. Des. Vol. 87,2009, pp. 233-243.

[11] R. Jamshidi, S. F, Ghomi, and B. Karimi, "Multiobjective green supply chain optimization with a new, hybrid memetic algorithm using the Taguchi method," Scientia Iranica, vol. 19, No. 6, 2012, pp. 1876-1886.

[12] S. H. Amin, and G. Zhang, "A multi-objective facility location model for closed-loop supply chain network under uncertain demand and return," Applied Mathematical Modelling, vol. 37, No. 6,2013, 416.

[13] Y.L. Lai, and C.L. Hwang, 1992. "Fuzzy mathematical programming," 1st ed., Springer: Berlin, 1992. 